\title{
Calcium/Calmodulin-Dependent Protein Kinase Type II Subunit Gamma
}

National Cancer Institute

\section{Source}

National Cancer Institute. Calcium/Calmodulin-Dependent Protein Kinase Type // Subunit

Gamma. NCl Thesaurus. Code C104835.

Calcium/calmodulin-dependent protein kinase type II subunit gamma (558 aa, $\sim 63 \mathrm{kDa}$ ) is encoded by the human CAMK2G gene. This protein is involved in calcium signaling. 